\title{
PERSPECTIVE
}

\section{Use of isolated ocular arteries in vitro to define the pathology of vascular changes in glaucoma}

\author{
Christine H Buckley, Patrick W F Hadoke, Colm J O’Brien
}

Glaucoma is a disease in which there is a progressive loss of visual field and a characteristic alteration in the appearance of the optic nerve head. ${ }^{1}$ While the exact pathogenesis of this condition remains unclear, a significantly increased intraocular pressure (IOP) has been clearly shown to lead to damage to the optic nerve head, ${ }^{2}$ and current treatment for glaucoma consists almost entirely of interventions which lower IOP. However, some patients with glaucomatous damage have an IOP within the normal range and in some cases of glaucoma reduction of IOP to normal values does not prevent the progression of the disease, indicating that factors other than an increased IOP may be involved in the development of this condition. ${ }^{3} \mathrm{~A}$ vascular role in the pathogenesis of glaucoma, as well as in other ocular diseases, has been suggested by the association between many systemic vascular diseases (including hypertension, migraine, diabetes, and peripheral vascular disease) and the presence of glaucoma. The systemic microcirculation and ocular blood flow, which are essential for the normal function of the optic nerve head, are both impaired in these disorders. Vascular factors may be of particular importance in normal pressure or low tension glaucoma which accounts for approximately one third of all glaucoma cases and in which IOP is normal. The presence of optic disc haemorrhages among patients with low tension glaucoma, indicating ischaemic optic microinfarction or vascular insufficiency to the optic nerve head, provides further support for a vascular role in the aetiology of this type of glaucoma. ${ }^{4-6}$

Clarification of the vascular alterations during disease progression in the eye is complicated by the limited information available concerning the normal physiological control of ocular blood vessels and their role in maintaining the normal function of the eye. While the eye is one of the most highly perfused organs in the body, the reasons for this are unclear. ${ }^{7}$ In humans the ophthalmic artery branches from the internal carotid artery and then divides to form the ocular blood vessels with the blood supply to the eye separating into two vascular systems. As the ophthalmic artery crosses the optic nerve it divides into the central retinal artery and posterior and anterior ciliary arteries. The retinal vessels supply the inner layers of the retina whereas the uveal or ciliary vessels supply the optic nerve head, choroid, iris, and ciliary body. ${ }^{7}$

In order to understand the role of ocular blood flow in both normal and pathological conditions, knowledge of the pharmacological control mechanisms involved in the ocular vascular bed is needed. While in vitro experiments, using isolated ring segments of arteries, provide a useful approach to gaining this information, such work has been restricted by the dimensions of ocular vessels. Indeed, early work was limited to the use of smooth muscle strip preparations, ${ }^{8}$ a technique which is still used for the study of some larger arteries. ${ }^{9-12}$ This problem has been overcome by the development of the small vessel myograph by Mulvany and Halpern, ${ }^{13}$ which allows analysis of vessels with an internal diameter as small as $100 \mu \mathrm{m}$. Comparatively recent work using wire myograph systems has provided some insights into the regulation of ocular blood vessels (reviewed in Haefliger et al ${ }^{14}$ and Brown and Jampol ${ }^{15}$ ). Furthermore, a small amount of work has been performed using a perfused whole eye preparation. ${ }^{16}{ }^{17}$ An additional technique which should prove to be important in this area is pressure myography. This technique allows investigation of the responses of vessels, similar in size to those used in the wire myograph, following cannulation and the intraluminal application of physiological salt solution. This produces an environment for the vessel which is closer to the in vivo situation than that produced in the wire myograph and, consequently, it has been demonstrated that vessels in a wire myograph are less sensitive to a variety of agonists than vessels in a pressure system or in vivo. ${ }^{18}$ Interpretation of the work performed using ocular vessels in vitro is difficult as many different ocular arteries and a wide variety of vasoactive agents have been utilised in varying degrees (Table 1). Furthermore, the inherent difficulties encountered in obtaining human tissue have led to the use of vessels from several different species of animal. This is important as there is well documented heterogeneity of vascular response between species, ${ }^{50}$ which complicates extrapolation of these results to the human.

This review aims to summarise the in vitro vasoactive studies carried out to date using various ocular arteries isolated from a number of different species, and to discuss the mechanisms that may be important in maintaining the vascular tone of these vessels. Finally, the review will consider how these systems may become impaired in glaucoma and the relevance of particular arteries and species used in glaucoma research.

\section{Dilator responses}

THE NITRIC OXIDE SYSTEM

Acetylcholine (ACh) induces relaxation in a large number of vascular smooth muscle preparations. ${ }^{51}$ In many arteries the dilator response is dependent on the presence of an intact layer of endothelial cells, ${ }^{52}$ and is due to the release of nitric oxide (NO) from the endothelium following stimulation of specific endothelial cell receptors (Fig 1). Several agonists and physical stimuli have now been shown to evoke endothelium dependent relaxations, although there is great heterogeneity in the responses. Many agents only elicit endothelium dependent relaxation in certain species, 
Table 1 Different ocular arteries used in in vitro studies

\begin{tabular}{lll}
\hline Species & Vessel & References \\
\hline Human & Ophthalmic artery & 19 \\
& Posterior ciliary artery & $20-24$ \\
Pig & Ophthalmic artery & 25,26 \\
& Ciliary artery & $17,26-29$ \\
& Retinal artery & 30 \\
& Perfused eye & 16,17 \\
Cow & Posterior ciliary artery & $5,31-33$ \\
& Retinal artery & $31,34-40$ \\
Dog & Ophthalmic artery & $6,10,11,41,42$ \\
& Posterior ciliary artery & $41-43$ \\
& Retinal artery & 12,44 \\
Cat & Ophthalmic artery & 45,46 \\
\multirow{2}{*}{ Rabbit } & Retinal artery & 47 \\
& Ophthalmic artery & 48,49 \\
\hline
\end{tabular}

or in specific vessels from certain species, and may cause contraction or endothelium independent relaxation in other preparations. Nitric oxide is formed from the amino acid L-arginine by the enzyme nitric oxide synthase (NOS), and its synthesis can be inhibited by analogues of L-arginine such as L-N ${ }^{G}$ monomethyl arginine (L-NMMA) or L-N ${ }^{G}$ nitroarginine methylester (L-NAME) ${ }^{53}{ }^{54}$ Relaxation of vascular smooth muscle by nitric oxide is mediated by the activation of soluble guanylate cyclase leading to an increase in intracellular cyclic guanosine monophosphate (cGMP) levels. ${ }^{55}$ By using pharmacological inhibitors of the L-arginine-nitric oxide pathway, such as methylene blue, which inhibits guanylate cyclase, or haemoglobin, which binds to and inactivates nitric oxide, as well as NOS inhibitors, the mechanism of action of receptor agonists and the role of nitric oxide and the endothelium in the regulation of blood flow can be determined (Fig 1).

BASAL NITRIC OXIDE RELEASE

In isolated quiescent bovine retinal arteries ${ }^{38}$ and porcine and human ophthalmic arteries ${ }^{192526}$ inhibitors of nitric oxide formation induced endothelium dependent contractions. In addition, in the whole perfused porcine eye, L-NAME was found to decrease ophthalmic blood flow by $40 \% .{ }^{16}$ Furthermore, in vivo studies have shown that intravenous infusion of NOS inhibitors results in a decreased blood flow in the choroid of cats ${ }^{56}$ and of choroid, ciliary body, and iris of dogs. ${ }^{57}$ Canine retinal blood flow, however, did not change significantly following treatment with L-NAME.$^{57}$ In contrast, in miniature pigs, nitric oxide is continuously produced by cells of the retina and this was reduced by inhibition of NOS resulting in retinal vasoconstriction. ${ }^{58}$ Studies in rabbits have also demonstrated a $50 \%$ reduction in both uveal and retinal blood flow following inhibition of NOS. ${ }^{59}$ These studies indicate that nitric oxide is important in regulating both uveal and retinal blood flow under resting conditions, although differences between species may exist. Treatment with L-NMMA or removal of the endothelium have also been shown to augment 5-hydroxytryptamine (5-HT) evoked contractions of porcine ophthalmic artery. ${ }^{25} 26$ These results show that the endothelium continuously produces nitric oxide which maintains the ophthalmic circulation in a constantly dilated state and may have a protective role against vasospasm.

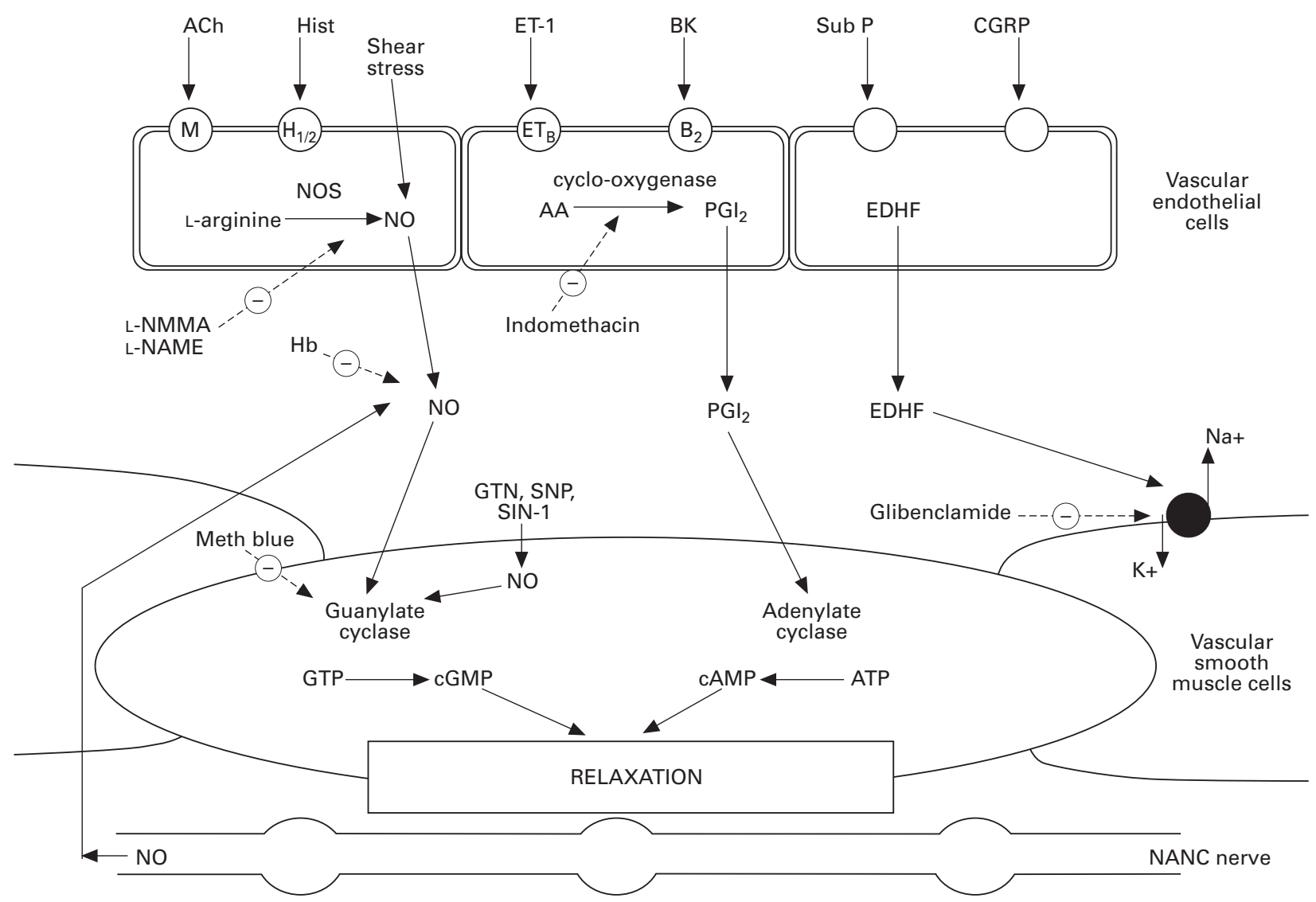

Figure 1 Mechanism of endothelium dependent relaxation showing the release of nitric oxide (NO), prostacyclin (PGI $)_{2}$ and endothelium derived hyperpolarising factor $(E D H F)$ from the endothelium. Agonists act on specific endothelial cell receptors and may stimulate the release of one or all mediators to induce smooth muscle relaxation. Abbreviations: Acetylcholine (ACh), histamine (Hist), endothelin-1 (ET-1), bradykinin (BK), substance P $($ Sub $P)$, calcitonin gene related peptide (CGRP), nitric oxide synthase (NOS), arachidonic acid (AA), $L-N^{G}$ monomethyl arginine $(L-N M M A), L-N^{G}$ nitroarginine methylester (L-NAME), haemoglobin (Hb), glyceryl trinitrate (GTN), sodium nitroprusside (SNP), 3-morpholinosydnonimine (SIN-1), methylene blue (Meth blue), cyclic guanosine/adenosine monophosphate (cGMP/cAMP), guanosine/adenosine triphosphate (GTP/ATP), non-adrenergic non-cholinergic (NANC), muscarinic receptor $(M)$, histamine receptor $\left(H_{1 / 2}\right)$, endothelin $B$ receptor $\left(E T_{B}\right)$, bradykinin receptor $\left(B_{2}\right)$. 
AGONIST INDUCED NITRIC OXIDE RELEASE

ACh evoked relaxations in isolated bovine retinal arteries, ${ }^{38}$ porcine ophthalmic arteries, ${ }^{25}$ and human posterior ciliary and ophthalmic arteries, ${ }^{19}{ }^{21}$ which were abolished on removal of the endothelium. In contrast, relaxations evoked by ACh in canine ophthalmic and retinal arteries were not dependent on an intact endothelium but were mediated by the release of prostacyclin $\left(\mathrm{PGI}_{2}\right)$ from subendothelial tissues ${ }^{912}$ indicating that some heterogeneity between species exists. Endothelium dependent relaxations in response to histamine, bradykinin, and substance $P$ have also been demonstrated in isolated bovine and canine retinal arteries, ${ }^{38} 3944$ porcine and human ophthalmic arteries, ${ }^{192526}$ and porcine ciliary artery. ${ }^{17262729}$ The endothelium dependent relaxation elicited by $\mathrm{ACh}$ was completely abolished by atropine, methylene blue, and L-NMMA, ${ }^{1923844}$ indicating that the response was mediated by activation of endothelial muscarinic receptors stimulating the release of nitric oxide. In addition, in vivo experiments have demonstrated an increased choroidal blood flow in response to intravenous infusion of $\mathrm{ACh}$ which was reduced following co-infusion of the NOS inhibitor $\mathrm{N}^{\mathrm{G}}$ nitro-L-arginine, ${ }^{56}$ suggesting a role for nitric oxide in the control of choroidal blood flow.

In the intact perfused porcine eye, bradykinin resulted in a concentration dependent increase in ophthalmic flow which was completely prevented by L-NAME, ${ }^{16}$ suggesting that nitric oxide is the primary mediator of the vasodilatory response to bradykinin. In contrast, studies using isolated porcine ophthalmic and ciliary arteries demonstrated that the relaxing effect of bradykinin was markedly reduced, but not abolished, by L-NMMA ${ }^{25}{ }^{26}$ indicating that nitric oxide contributes only in part to the relaxation and a relaxing factor distinct from nitric oxide, possibly endothelium derived hyperpolarising factor, may also be involved. Furthermore, the bradykinin stimulated release of nitric oxide increased with decreasing vessel diameter in the porcine extraocular ophthalmic circulation, ${ }^{26}$ indicating that endothelium mediated responses can be influenced by vessel size.

The endothelium dependent relaxation evoked by histamine in bovine retinal and human ophthalmic arteries was mediated mainly by activation of endothelial $\mathrm{H}_{1}$ receptors. ${ }^{1939}$ In bovine retinal arteries, the relaxation was completely abolished by methylene blue and also partly blocked by indomethacin ${ }^{39}$ which may indicate that the response was mediated by both nitric oxide and a cyclo-oxygenase product such as $\mathrm{PGI}_{2}$. In human arteries, however, the relaxation did not involve $\mathrm{PGI}_{2}$ and was only partially blocked by L-NAME, the remainder of the response being sensitive to inhibition by an $\mathrm{H}_{2}$ receptor antagonist. ${ }^{19}$ The dilator response to histamine in canine ophthalmic artery depends on the anatomical location of the vessel; in the internal ophthalmic artery the relaxation was independent of the endothelium and mediated by $\mathrm{H}_{2}$ receptors located on the vascular smooth muscle. ${ }^{10}$ Histamine induced relaxation in the canine external ophthalmic artery, however, was partly endothelium dependent mediated by endothelial $\mathrm{H}_{1}$ receptors causing the release of $\mathrm{PGI}_{2}$ with the remaining response mediated by direct activation of smooth muscle $\mathrm{H}_{2}$ receptors. ${ }^{10}$ These dilator actions, observed in response to histamine in bovine retinal and human and canine ophthalmic arteries, are in marked contrast to the contractile responses seen in bovine ciliary and cat ophthalmic arteries when stimulated with histamine. ${ }^{846}$ Nitric oxide is therefore released from the endothelium both under basal conditions and following stimulation with agonists such as acetylcholine or bradykinin.
NEURONAL NITRIC OXIDE

In addition to mediating vasodilation following release from the endothelium, nitric oxide has also been implicated as a neurotransmitter responsible for the non-adrenergic non-cholinergic (NANC) vasodilator response in both the peripheral and central nervous systems. ${ }^{60} 61$ The ocular circulation is innervated by nerves containing a number of neurotransmitters including noradrenaline and acetylcholine as well as a variety of neuropeptides. ${ }^{62}$ Using immunohistochemical techniques, the presence of NOS containing neurons has been demonstrated in ocular tissues of rat, rabbit, and human origin. ${ }^{63}{ }^{64}$ In the rat, NOS activity is localised in peripheral parasympathetic nerve fibres derived from the pterygopalatine ganglion and supplying mainly the choroid and limbal vessels as well as in a number of retinal cell types. ${ }^{63}$ Studies using human eyes have also shown a wide distribution of NOS in the choroid. ${ }^{64}$ In support of a neurotransmitter role for nitric oxide in the ocular circulation, studies using transmural electrical stimulation of isolated arteries have shown that nerves innervating human and bovine long posterior ciliary arteries and also canine ophthalmic arteries release nitric oxide which mediates vasodilatation. $^{112432}$

OTHER DILATOR AGONISTS

$\beta$ Adrenoceptor antagonists are widely used in the treatment of glaucoma to lower IOP, although the mechanism involved in their therapeutic efficacy is not fully understood and effects on blood flow may also contribute to their effectiveness in glaucoma treatment. $\beta$ Blockers, such as betaxolol and timolol, have been found to relax bovine retinal arteries precontracted with $\mathrm{KCl}$ and $5-\mathrm{HT}^{36}$ and also porcine posterior ciliary arteries activated with $\mathrm{KCl}$ and the thromboxane mimetic $\mathrm{U} 46619^{28}$ by a mechanism not related to inhibition of adrenoceptors nor to the local anaesthetic properties of the drugs. However, owing to the similar relaxation properties of $\beta$ blockers and $\mathrm{Ca}^{2+}$ antagonists, it was suggested that the relaxation of ocular arteries evoked by the $\beta$ adrenoceptor antagonists was due to their $\mathrm{Ca}^{2+}$ antagonistic properties. ${ }^{2836}$

The relaxing effect of $\mathrm{Ca}^{2+}$ antagonists has also been demonstrated in other studies using bovine retinal arteries precontracted with $\mathrm{KCl}, \mathrm{PGF}_{2 \alpha}{ }^{35}$ and ET-1, ${ }^{40}$ with $\mathrm{KCl}$, but not noradrenaline, in canine ophthalmic and long posterior ciliary arteries, ${ }^{4143}$ and with $\alpha_{1}$ agonists in cat ophthalmic arteries ${ }^{45}$ and porcine ciliary arteries contracted with ET-1. ${ }^{29}$ These studies indicate that the contractions to these agonists are dependent, at least in part, on an influx of extracellular $\mathrm{Ca}^{2+}$ through membrane potential operated calcium channels.

Some metabolites of arachidonic acid have been shown to elicit relaxation in ocular arteries. These include $\mathrm{PGI}_{2}$ in bovine retinal and canine ophthalmic arteries ${ }^{1037}$ and prostaglandin $\mathrm{E}_{2}\left(\mathrm{PGE}_{2}\right)$ in canine ophthalmic artery. ${ }^{10}$ In bovine retinal arteries, however, $\mathrm{PGE}_{2}$ has been shown to evoke concentration dependent contractions. ${ }^{37} \mathrm{PGI}_{2}$ can also be released from the endothelium, in response to chemical or mechanical stimulation, mediating relaxation through the activation of adenylate cyclase and the formation of cAMP.

\section{Constrictor responses}

ADRENOCEPTOR AGONISTS

Canine ophthalmic and long posterior ciliary arteries have been shown to contract in response to $5-\mathrm{HT}$, noradrenaline, adrenaline, and the selective $\alpha_{1}$ agonist, phenylephrine but not to $\alpha_{2}$ selective agonists. ${ }^{412}$ In addition, some heterogeneity in the responses to the agonists was 
described in canine long posterior ciliary arteries, depending on the exact anatomical location of the vessel. ${ }^{43}$

Similar studies using ophthalmic artery rings from the cat have concluded that in this artery functional histamine, 5-HT, and $\alpha_{1}$ adrenergic receptors mediating contraction are present whereas $\alpha_{2}$ and $\beta$ adrenoceptors are absent. ${ }^{46}$ Again differences in sensitivity to these agonists existed between proximal and distal segments of the artery.

Isolated human posterior ciliary arteries and ophthalmic and ciliary arteries from monkeys have similarly been shown to contract in response to 5-HT, noradrenaline, and $\alpha_{1}$ adrenoceptor agonists but not to $\alpha_{2}$ selective agonists. $^{202365}$

Similar results were obtained in studies using bovine long posterior ciliary arteries with contractions seen in response to histamine, 5-HT, and noradrenaline. ${ }^{8}$ The noradrenaline induced contraction in this artery was mediated by $\alpha$ adrenergic receptors with a lack of response to $\beta$ agonists. ${ }^{8}$ Bovine retinal and choroidal arteries have also been shown to evoke no response to $\beta$ adrenoceptor agonists $^{3334}$ indicating a lack of functional $\beta$ adrenoceptors in these arteries. However, using radioligand binding and autoradiographic techniques, the presence of $\beta$ adrenoceptors has been demonstrated in the ocular circulation, particularly $\beta_{2}$ adrenoceptors around the ciliary body and also in bovine retinal arteries. ${ }^{66-68}$

\section{ARACHIDONIC ACID DERIVATIVES}

Derivatives of arachidonic acid have a number of vasoactive properties and have been implicated in the autoregulation of retinal blood flow as well as in a number of ocular vascular disorders. In contrast with the arachidonic acid derivatives described previously which mediated relaxation in isolated ocular arteries, $\mathrm{PGF}_{2 \alpha}$ is widely used as a contractile agonist in many isolated arterial preparations including a number of ocular arteries of human, ${ }^{2024}$ monkey, ${ }^{65}$ bovine, ${ }^{333537-40}$ and canine ${ }^{9-12}{ }^{42-44}$ origin. $\mathrm{PGD}_{2}, \mathrm{PGE}_{2}$ and stable thromboxane $\mathrm{A}_{2}$ analogues have also been shown to evoke contractions in ocular arteries. ${ }^{10282937}$ These contractile responses are thought to be mediated by a direct effect on specific prostanoid receptors located on vascular smooth muscle cells. In addition, cyclo-oxygenase derived contracting factors can be released from the vascular endothelium of porcine ophthalmic arteries in response to mechanical stretching ${ }^{25}$ providing a mechanism of local blood flow autoregulation.

\section{THE RENIN-ANGIOTENSIN SYSTEM}

The renin-angiotensin system is involved in the regulation of a number of physiological functions including blood pressure and electrolyte homeostasis. Angiotensin II (AII) is formed from the less active precursor angiotensin I by the action of angiotensin converting enzyme (ACE) and is a potent vasoconstrictor agent. ACE also degrades bradykinin, while angiotensin II upregulates the expression of endothelin-1 messenger (m)RNA in cultured endothelial cells. ${ }^{69}{ }^{70}$ Inhibitors of ACE, therefore, not only inhibit the formation of AII, but also increase the levels of bradykinin, which activates the nitric oxide pathway, and reduce the formation of the vasoconstrictor peptide, endothelin-1.

The existence of a renin-angiotensin system has been shown in the ocular circulation by specific radioligand binding studies demonstrating the presence of AII binding sites in both human and bovine retinal vessels. ${ }^{71}{ }^{72}$ In addition, high levels of ACE have been detected in choroidal and retinal vessels of bovine, feline, and human origin. ${ }^{73-75}$ Furthermore, using reverse transcription polymerase chain reaction (RT-PCR) techniques, gene expression of compo- nents of the renin-angiotensin system has been demonstrated in the choroid and retina of human eyes, supporting the existence of intraocular synthesis of AII. ${ }^{76}$ Bovine retinal arteries have, however, been shown to be insensitive to the in vitro application of AII. ${ }^{31}$ In contrast, concentration dependent contractions to AII have been demonstrated in isolated bovine, porcine, and human posterior ciliary arteries ${ }^{172231}$ and in retinal arteries of the cat. ${ }^{47}$ Owing to the development of a marked tachyphylaxis these results may indicate however, that AII is not an important factor in the regulation of resting ocular blood flow in vivo. These results must, however, be treated with caution as some arteries which fail to respond to AII in the wire myograph may produce concentration dependent contractions in a pressure system. ${ }^{18}$ Furthermore, the site of action may be important since in retinal vessels intra-arterial AII may be prevented from reaching the smooth muscle cells by the blood-retinal barrier. This would be difficult to investigate in the wire myograph as vasoactive compounds have access to both intra- and extraluminal cells, but use of the perfusion system would allow them to be introduced either via the lumen or to the outside of the vessel. ${ }^{30}$

In the isolated perfused porcine eye, ACE inhibitors reduced the vasoconstriction evoked by AII and also enhanced bradykinin induced vasodilation. ${ }^{17} \mathrm{ACE}$ inhibitors had no effect, however, on resting vascular tone in the perfused porcine eye ${ }^{17}$ indicating that baseline levels of AII or bradykinin are not important in the regulation of vascular tone and resting blood flow in the ocular circulation. An activated renin-angiotensin system may, however, be involved in a number of diseases of the eye, including diabetic retinopathy in which increased levels of renin and angiotensin II have been detected in the vitreous fluid from these patients, and glaucoma in which angiotensin II has been implicated as a possible mediator of optic nerve damage. ${ }^{77}$ Angiotensin II may also play a part in the regulation of aqueous outflow and therefore IOP since local application of ACE inhibitors lowers IOP. ${ }^{78}$

ENDOTHELIN-1

The endothelins (ET) are a family of 21 amino acid peptides of which three isoforms exist: ET-1, ET-2, and ET-3. ET-1 is produced and released by endothelial cells and induces vasoconstriction in a number of vascular beds following intravenous infusion and evokes potent contractions of isolated arteries and veins. ${ }^{79}$ In some vascular beds ET-1 will produce vasodilatation at low doses, with contraction produced by higher concentrations of the peptide. This dual action of ET-1 is the result of two different $\mathrm{ET}$ receptors: $\mathrm{ET}_{\mathrm{A}}$ and $\mathrm{ET}_{\mathrm{B}}$. $\mathrm{ET}_{\mathrm{B}}$ receptors are located predominantly on endothelial cells (but are also present on vascular smooth muscle cells) and mediate a vasodilatory response via the release of nitric oxide and $\mathrm{PGI}_{2}$ while the vasoconstriction results from activation of $\mathrm{ET}_{\mathrm{A}}$ receptors located on the vascular smooth muscle cells. The production of ET- 1 is limited by nitric oxide and $\mathrm{PGI}_{2}$, and it has been demonstrated in vivo that the vasoconstrictor actions are augmented following inhibition of nitric oxide synthesis with L-NMMA (Fig 2).$^{80}$ This illustrates that a delicate balance exists between endothelium mediated vasodilatation and vasoconstriction and that endothelium derived mediators play a significant role in the local regulation of blood flow. The importance of ET-1 in the ophthalmic circulation is highlighted by the presence of high levels of the peptide in ocular tissues of human, rat, porcine, and rabbit origin. ${ }^{81}$

In the ocular circulation ET-1 has been shown to elicit contraction in porcine ophthalmic and ciliary arteries, ${ }^{252629}$ bovine retinal artery, ${ }^{40}$ and human ophthalmic artery. ${ }^{19}$ The response to ET-1 in most vessels was not sustained 


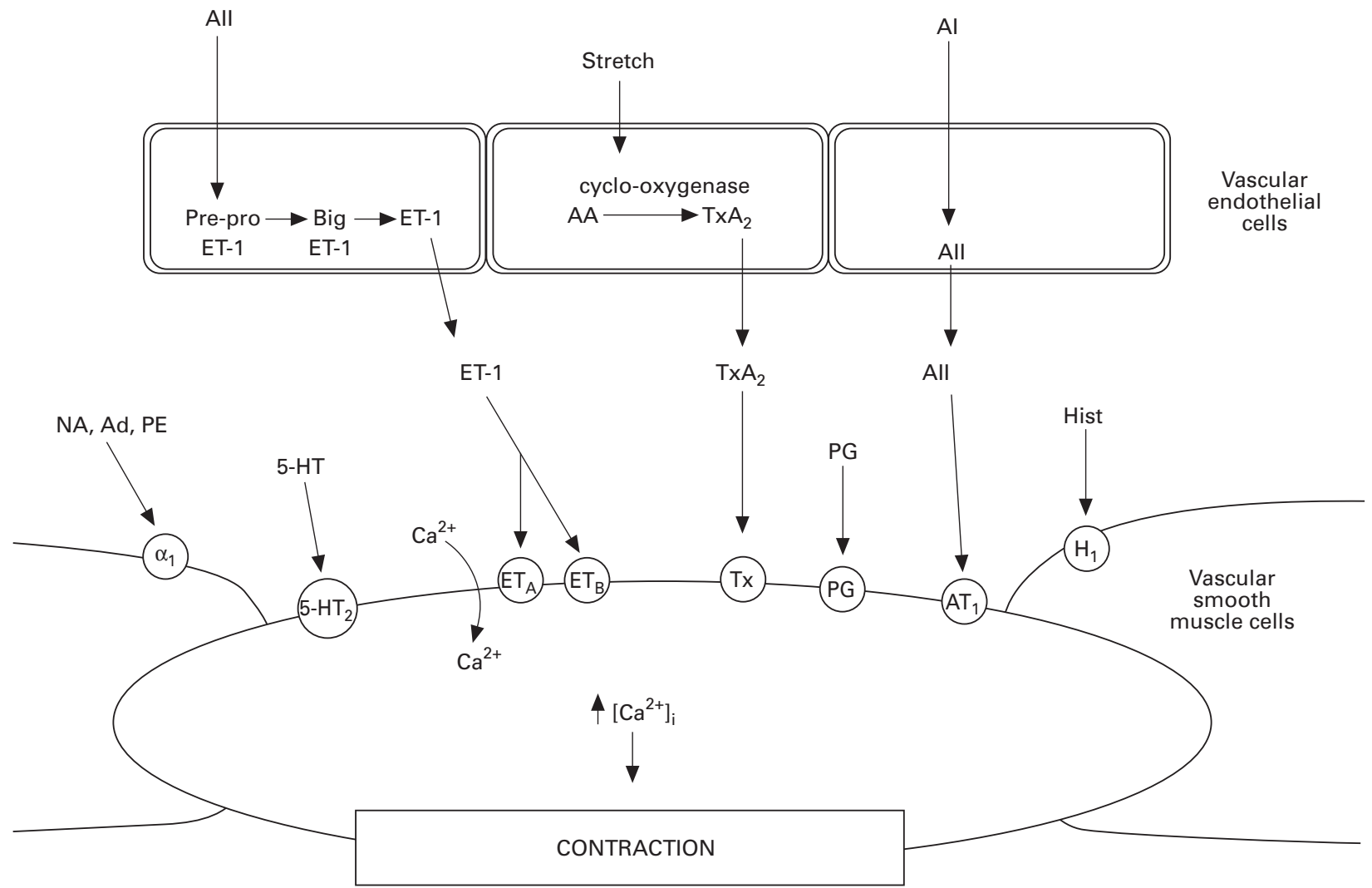

Figure 2 Mechanism of agonist induced contraction showing the release of contracting factors endothelin-1 (ET-1), thromboxane $A_{2}$, (Tx $\left.A_{2}\right)$, and angiotensin II (AII) from the endothelium, as well as the direct stimulation of smooth muscle cell receptors by agonists to increase intracellular calcium $\left(\left[\mathrm{Ca}^{2+}\right]_{i}\right)$ and induce smooth muscle contraction. Abbreviations: Preproendothelin-1 (Pre-pro ET-1), big endothelin-1 (Big ET-1), arachidonic acid (AA), angiotensin I (AI), angiotensin converting enzyme (ACE), noradrenaline (NA), adrenaline (Ad), phenylephrine (PE), 5-hydroxytryptamine (5-HT), prostaglandins $(P G)$, histamine (Hist), $a_{1}$ adrenoceptor $\left(a_{1}\right)$, endothelin receptors $\left(E T_{A}, E T_{B}\right)$, thromboxane receptor (Tx), angiotensin receptor $\left(A T_{1}\right)$, histamine receptor $\left(H_{1}\right)$.

and re-exposure to the peptide resulted in a marked tachyphylaxis ${ }^{1926}$ which may be due to a down regulation of endothelin receptors. This may provide a protective mechanism against prolonged exposure to ET-1. In bovine and porcine vessels the ET-1 induced contraction was partly reversed by voltage operated calcium channel blockers ${ }^{29}{ }^{40}$; in human ophthalmic artery, however, calcium antagonists had no effect on the contractile response to ET- $1 .{ }^{19}$ In some species, therefore, ET-1 induced contraction is mediated in part by an influx of extracellular calcium through

Table 2 Responses of ocular arteries to dilator agonists

\begin{tabular}{|c|c|c|c|c|c|}
\hline Agonist & Artery & Species & Endothelium dependent & Receptor & Mediator \\
\hline \multirow[t]{6}{*}{ Acetylcholine } & Ophthalmic: & human, porcine & + & & NO \\
\hline & & canine & - & $\mathrm{M} / \mathrm{N}$ & $\mathrm{PGI}_{2} / \mathrm{NO}$ (neurogenic) \\
\hline & & feline & + & & \\
\hline & Ciliary: & human, porcine & + & & \\
\hline & Retinal: & bovine & + & M & NO \\
\hline & & canine & - & $\mathrm{M} / \mathrm{N}$ & $\mathrm{PGI}_{2} / \mathrm{NO}$ (neurogenic) \\
\hline \multirow[t]{3}{*}{ Bradykinin } & Ophthalmic: & human & + & & NO \\
\hline & & porcine & + & & $\mathrm{NO} / \mathrm{EDHF} ?$ \\
\hline & Ciliary: & porcine & + & $\mathrm{B}_{2}$ & $\mathrm{NO} / \mathrm{EDHF}$ ? \\
\hline \multirow[t]{4}{*}{ Histamine } & Ophthalmic: & $\begin{array}{l}\text { human } \\
\text { canine }\end{array}$ & + & $\mathrm{H}_{1} / \mathrm{H}_{2}$ & $\mathrm{NO} / ?$ \\
\hline & external & & $+/-$ & $\mathrm{H}_{1} / \mathrm{H}_{2}$ & $\mathrm{PGI}_{2}$ \\
\hline & internal & & - & $\mathrm{H}_{2}$ & Not $\mathrm{PGI}_{2}$ \\
\hline & Retinal: & bovine & + & $\mathrm{H}_{1} / \mathrm{H}_{2}$ & $\mathrm{NO} / \mathrm{PGI}_{2}$ \\
\hline \multirow[t]{2}{*}{ Substance P } & Ophthalmic: & canine & + & & $\mathrm{NO} / \mathrm{PGI}_{2}$ \\
\hline & Retinal: & canine & + & & $\mathrm{NO}$ \\
\hline \multirow[t]{2}{*}{$\beta$ Antagonists } & Ciliary: & porcine & - & & $\mathrm{Ca}^{2+}$ antagonism? \\
\hline & Retinal: & bovine & - & & $\mathrm{Ca}^{2+}$ antagonism? \\
\hline \multirow[t]{2}{*}{$\mathrm{PGI}_{2}$} & Ophthalmic: & canine & & & \\
\hline & Retinal: & bovine & & & \\
\hline $\mathrm{PGE}_{2}$ & Ophthalmic: & canine & & & \\
\hline \multirow[t]{3}{*}{$\mathrm{SNP}^{2}$} & Ophthalmic: & canine & - & & \\
\hline & Ciliary: & human, porcine, canine & - & & \\
\hline & Retinal: & bovine & - & & \\
\hline \multirow[t]{2}{*}{ SIN-1 } & Ophthalmic: & porcine & - & & \\
\hline & Ciliary: & porcine & - & & \\
\hline GTN & Retinal: & canine & - & & \\
\hline NO & Ophthalmic: & canine & - & & \\
\hline
\end{tabular}

Muscarinic/nicotinic receptor (M/N), nitric oxide (NO), prostacyclin $\left(\mathrm{PGI}_{2}\right)$, bradykinin receptor $\left(\mathrm{B}_{2}\right)$, endothelium derived hyperpolarising factor $(\mathrm{EDHF})$, histamine receptor $\left(\mathrm{H}_{1} / \mathrm{H}_{2}\right)$, prostaglandin $\mathrm{E}_{2}\left(\mathrm{PGE}_{2}\right)$, sodium nitroprusside (SNP), 3-morpholinosydnonimine (SIN-1), glyceryl trinitrate (GTN). 
Table 3 Responses of ocular arteries to constrictor agonists

\begin{tabular}{|c|c|c|c|c|}
\hline Agonist & Artery & Species & Receptor & Mechanisms \\
\hline \multirow[t]{2}{*}{ Noradrenaline } & $\begin{array}{l}\text { Ophthalmic: } \\
\text { Ciliary: }\end{array}$ & $\begin{array}{l}\text { porcine, canine, feline } \\
\text { human }\end{array}$ & $\alpha_{1}$ & \\
\hline & Ophthalmic: & $\begin{array}{l}\text { bovine, canine } \\
\text { canine, feline }\end{array}$ & $\alpha_{1}$ & \\
\hline \multirow{2}{*}{ Adrenaline } & Ciliary: & human, canine & & \\
\hline & Retinal: & porcine & & \\
\hline \multirow{3}{*}{ Phenylephrine } & Ophthalmic: & canine, feline & $\alpha_{1}$ & \\
\hline & Ciliary: & human, canine & $\alpha_{1}$ & \\
\hline & Retinal: & bovine & $\alpha_{1}$ & \\
\hline \multirow{2}{*}{$\alpha_{2}$ Agonists } & Ophthalmic: & canine, feline & & No contraction \\
\hline & Ciliary: & human, canine & & No contraction \\
\hline \multirow[t]{5}{*}{ 5-HT } & Ophthalmic: & human, feline & & \\
\hline & & porcine & $5-\mathrm{HT}_{2}$ & \\
\hline & Ciliary: & $\begin{array}{l}\text { rabbit } \\
\text { human }\end{array}$ & $5-\mathrm{HT}_{1 / 2}$ & \\
\hline & & porcine, bovine & $5-\mathrm{HT}_{2}$ & \\
\hline & Retinal: & bovine & & \\
\hline \multirow[t]{3}{*}{ Histamine } & Ophthalmic: & feline & & \\
\hline & Ciliary: & human & & \\
\hline & & bovine & $\mathrm{H}_{1}$ & \\
\hline \multirow{3}{*}{ Angiotensin II } & Ciliary: & human, bovine & & \\
\hline & Retinal. & porcine & $\mathrm{AT}_{1}$ & No contraction \\
\hline & Retinal: & feline & $\mathrm{AT}_{1}$ & No contraction \\
\hline \multirow[t]{3}{*}{ Endothelin-1 } & Ophthalmic: & $\begin{array}{l}\text { human } \\
\text { porcine }\end{array}$ & & PLC activation? \\
\hline & Ciliary: & $\begin{array}{l}\text { pormine } \\
\text { porcine }\end{array}$ & & Influx extracellular $\mathrm{Ca}^{2+}$ \\
\hline & Retinal: & bovine & & Influx extracellular $\mathrm{Ca}^{2+}$ \\
\hline \multirow[t]{3}{*}{$\mathrm{PGF}_{2 \alpha}$} & Ophthalmic: & porcine, canine & & \\
\hline & Ciliary: & porcine, bovine, canine & & \\
\hline & Retinal: & bovine & & \\
\hline \multirow{5}{*}{$\begin{array}{l}\mathrm{PGD}_{2} \\
\mathrm{PGE}_{2} \\
\mathrm{TxA}_{2} / \mathrm{U} 46619\end{array}$} & Ophthalmic: & canine & & \\
\hline & Retinal: & bovine & & \\
\hline & Ophthalmic: & canine & & \\
\hline & Ciliary: & porcine & & \\
\hline & Retinal: & bovine & & \\
\hline
\end{tabular}

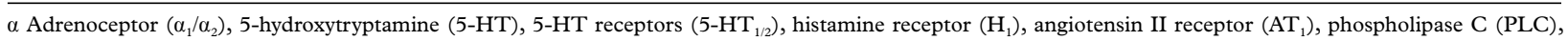
prostaglandins ( $\mathrm{PG})$, thromboxane $\mathrm{A}_{2}\left(\mathrm{TxA}_{2}\right)$.

voltage operated calcium channels and partly through other mechanisms such as the activation of phospholipase $\mathrm{C}$ and release of intracellular calcium. The porcine extraocular ophthalmic circulation shows some degree of heterogeneity in the response to ET-1 in that the sensitivity to the peptide increased with decreasing vessel diameter. ${ }^{26}$ This further demonstrates that the importance of endothelium dependent responses increases as the blood vessel diameter decreases, indicating a crucial role for these mechanisms in the regulation of the ophthalmic microcirculation. Although in isolated ocular arteries, from bovine, porcine and human origin, ET-1 only causes contraction, in the isolated perfused porcine eye vasodilatation is observed at low doses of ET-1 followed by a significant vasoconstriction at higher concentrations ${ }^{16}$ demonstrating the presence of both $\mathrm{ET}_{\mathrm{A}}$ and $\mathrm{ET}_{\mathrm{B}}$ receptors mediating constriction and dilatation respectively.

NEURONAL REGULATION

Regional variation exists in the innervation of the ocular circulation. Whereas several nerves regulate uveal blood flow, and extraocular and choroidal vessels are regulated by autonomic innervation, vasoactive nerves do not regulate blood flow through the retina or optic nerve. In the latter, autoregulatory mechanisms exist to maintain a relatively constant blood flow via mechanisms independent of changes in IOP or vascular perfusion pressure, although the presence of both adrenergic and cholinergic binding sites has been demonstrated. ${ }^{783}$ The role of these binding sites remains unclear and, in contrast with the investigations into NANC innervation, there appear to be no studies in which isolated vessels have been electrically stimulated to investigate the role of neurotransmitters.

\section{Vascular alterations in glaucoma}

A role for vascular alterations in glaucoma, ${ }^{3}$ proposed to explain deficiencies in the pressure theory, (reviewed in
Flammer ${ }^{84}$ ) suggests that impaired vascular responses (for example, increased vasospasm) combine with systemic alterations (for example, hypotension) to reduce ocular blood supply. This is supported by the observation that many glaucoma patients have widespread cerebrovascular and cardiovascular disease ${ }^{8586}$ and increased vasospasm (indicated by the prevalence of migraine ${ }^{87}$ and a Raynaud's-like peripheral circulation ${ }^{88}{ }^{89}$ ). Alterations in blood coagulation may also play a role in some types of glaucoma with evidence of an increase in both platelet adhesiveness and spontaneous platelet aggregation reported, ${ }^{8590}$ as well as an increase in plasma viscosity. ${ }^{91}$ Such abnormalities have also been found to be associated with myocardial infarction and cerebrovascular disease. Furthermore, increased plasma levels of ET-1 are seen in some types of glaucoma ${ }^{9293}$ and also in systemic cardiovascular (atherosclerosis, pulmonary hypertension, and chronic heart failure) ${ }^{94-97}$ and vasospastic (Raynaud's phenomenon and variant angina $)^{98-100}$ disorders.

The mechanisms underlying these vascular abnormalities remain unclear but may be due to an impaired release of NO from the vascular endothelium. Autoregulation, which may be regulated by local dilator and constrictor systems, ${ }^{84}$ has been demonstrated in the vessels of the retina, choroid, and optic nerve head. ${ }^{83101} 102$ This ensures that an increase in intraocular pressure, plus a decrease in perfusion pressure, stimulates a drop in vascular resistance which maintains an unchanged blood flow. ${ }^{103}$ In some conditions, autoregulation may be reduced, ${ }^{84}$ possibly as a result of endothelial cell dysfunction and a similar situation is seen in some cases of glaucoma in which autoregulation of retinal and optic nerve head blood flow is impaired. ${ }^{104} 105$ It has been shown that blood flow velocity in the central retinal, ophthalmic, and short posterior ciliary arteries is reduced in some cases of glaucoma. ${ }^{106-109}$ As the posterior ciliary artery provides the main source of blood supply to 
the optic nerve head, reduced blood flow in this vessel may lead to glaucomatous optic nerve damage.

\section{Use of isolated vessels in investigating the pathology of glaucoma}

The relatively small amount of work performed using ocular blood vessels in vitro is disparate using a variety of species, arteries, and vasoactive compounds. Little in depth analysis of signal transduction mechanisms has been performed in these arteries but such data that are available demonstrate heterogeneity not only between species and vessels, but also between different parts of the same vessel (Tables 2 and 3). Indeed, functional responses may alter markedly as the diameter of a vessel changes. ${ }^{26}$ This emphasises the need to select the most suitable species for use as vessel donors (when human vessels are unavailable), the need for certainty that the vessel chosen is relevant to the aims of the research, and care in ensuring that the vascular rings selected are taken from the same anatomical location each time.

The use of retinal vessels in vitro is attractive as this allows investigation of phenomena (for example, vasospasm) which have been observed in vivo. However, it may be that such alterations are more important, and more prevalent, in ciliary or choroidal blood vessels. ${ }^{84}$ Use of choroidal blood vessels, while possible in larger animals, is restricted by the difficulties encountered in the dissection of these vessels and the relatively small contractions they produce in vitro. ${ }^{33}$ In addition to being highly relevant to glaucoma research, ciliary arteries are possibly the most convenient for use in myograph systems as they are relatively simple to dissect, are a good size to handle and produce strong contractile responses. Anterior ciliary arteries will provide information on the regulation of blood flow to the ciliary processes at the front of the eye while the short posterior ciliary arteries provide information about blood flow to the optic nerve head. The regulation of blood flow to the entire eye may be usefully investigated using the ophthalmic artery but care is needed to ensure that the same portion of the vessel is taken for each experiment. It should also be remembered that altered venous regulation may contribute to changes which cause ischaemia in the eye $^{110}$ suggesting that assessment of venous, as well as arterial, function should be investigated in vitro. The feasibility of such investigations has been demonstrated by the use of bovine isolated aqueous veins in a wire myograph system. ${ }^{111}$ This may have the further advantage of allowing investigation of the outflow channels for aqueous humour which appear to be regulated in a manner similar to blood vessels. ${ }^{84}$ The practical and ethical difficulties encountered in obtaining human tissue, and the consequent use of arteries from experimental animals, have led to the need to extrapolate results to the human condition. The obvious need to use animals with an ocular circulation as similar to the human as possible is tempered by the cost and ethical concerns encountered with using non-human primates. Canine, bovine, and porcine eyes are the most useful for isolated vessel studies (Table 1) as the ophthalmic, ciliary, and retinal arteries are all of a suitable size for use in the myograph. Of these, the porcine eye is probably most similar to the human and this is reflected by the increasing body of work performed with both isolated vessel and perfused eye techniques from this source. Furthermore, the relaxant (Table 2) and contractile (Table 3) responses evoked in porcine vessels are similar (although not identical) to those which have been demonstrated in isolated human vessels. A final consideration, however, reflects the availability (and continued development) of animal models of glaucoma. In such cases, the identification of pathologi- cal alterations in vascular function will be of immense interest even if the animal (for example, the rabbit ${ }^{12}$ ) has an ocular circulation that is not identical to that in the human.

\section{Conclusions}

This review has described the important insights into the maintenance of ocular flow which have been gained using in vitro investigation. This work demonstrates the heterogeneity of responses between species, vessels, and different parts of the same vessel, indicating that the importance of nervous and autoregulatory control mechanisms varies between vessels and that the endothelium plays a key role in the maintenance of blood flow. Equilibrium between constrictor and dilator compounds released from the vascular endothelium may be central to the control of normal flow in the eye and derangements in this system may be implicated in the development of glaucoma and other ocular vascular diseases. Continued use of myographic techniques, coupled with the development of animal models, may enable clarification of the vascular changes in glaucoma. Furthermore, this technique will allow investigation of the vascular effects produced by therapies used in the treatment of this condition. Supported in part by grants from the Royal College of Surgeons of Edinburgh
and the Royal School for the Blind, Edinburgh. CHRISTINE H BUCKLEY

Departments of Ophthalmology and Medicine, Royal Infirmary, Edinburgh

PATRICK W F HADOKE

Department of Medicine,

Royal Infirmary, Edinburgh

COLM J O'BRIEN

Department of Ophthalmology,

Royal Infirmary, Edinburgh

Correspondence to: Dr C H Buckley, Department of Medicine, The Royal Infirmary, Lauriston Place, Edinburgh EH3 9YW.

1 Quigley HA. Open angle glaucoma. N Engl F Med 1993;328:1097-105.

2 Quigley HA, Addicks EM. Chronic experimental glaucoma in primates. II Effect of extended intraocular pressure elevation on optic nerve head and Effect of extended intraocular pressure elevation on optic n
axonal transport. Invest Ophthalmol Vis Sci 1980;19:137-52.

3 Fechtner RD, Weinreb RN. Mechanisms of optic nerve damage in primary open angle glaucoma. Surv Ophthalmol 1994;39:23-42.

4 Drance SM, Begg IS. Sector haemorrhage- a probable acute ischaemic disc change in chronic simple glaucoma. Can f Ophthalmol 1970;5:137-41.

5 Kitazawa Y, Shirata S, Yamamoto T. Optic disc haemorrhage in low tension glaucoma. Ophthalmology 1986;93:853-7.

6 Drance SM. Disc haemorrhages in the glaucomas. Surv Ophthalmol 1989;33:331-7.

7 Alm A, Bill A. Ocular circulation. In: Moses RA, Hart WM Jr, eds. Adler's physiology of the eye. St Louis: Mosby, 1987:183-203.

8 Dalske HF. Pharmacological reactivity of isolated ciliary arteries. Invest Ophthalmol 1974;13:389-92.

9 Wang Y, Okamura T, Toda N. Mechanisms of acetylcholine-induced relaxation in dog external and internal ophthalmic arteries. Exp Eye Res 1993;57: $275-81$.

10 Wang Y, Okamura T, Toda N. Mechanisms of histamine-induced relaxation in external and internal ophthalmic arteries. Invest Ophthalmol Vis Sci 1993;34:41-8.

11 Toda N, Kitamura Y, Okamura T. Functional role of nerve-derived nitric oxide in isolated dog ophthalmic arteries. Invest Ophthalmol Vis Sci 1995;36:563-70

12 Toda N, Zhang J-X, Ayajiki K, Okamura T. Mechanisms underlying endothelium-independent relaxation by acetylcholine in canine retinal and endothelium-independent relaxation by acetylcholine in canin

13 Mulvany MJ, Halpern W. Contractile properties of small arterial resistance vessels in spontaneously hypertensive and normotensive rats. Circ Res 1977;411:19-26.

14 Haefliger IO, Meyer P, Flammer J, Lüscher TF. The vascular endothelium as a regulator of the ocular circulation: a new concept in ophthalmology? Surv Ophthalmol 1994;39:123-32.

15 Brown SM, Jampol LM. New concepts of regulation of retinal vessel tone. Arch Ophthalmol 1996;114:199-204.

16 Meyer P, Flammer J, Lüscher TF. Endothelium-dependent regulation of the ophthalmic microcirculation in the perfused porcine eye: role of nitric oxide and endothelins. Invest Ophthalmol Vis Sci 1993;34:3614-21.

17 Meyer P, Flammer J, Lüscher TF. Local action of the renin-angiotensin system in the porcine ophthalmic circulation: effects of ACE-inhibitors and angiotensin receptor antagonists. Invest Ophthalmol Vis Sci 1995;36:55562 .

18 Dunn WR, Wellman GC, Bevan JA. Enhanced resistance artery sensitivity to agonists under isobaric compared with isometric conditions. $\mathrm{Am} \mathcal{F}$ Physiol 1994;266:H147-55. 
19 Haefliger IO, Flammer J, Lüscher TF. Nitric oxide and endothelin-1 are important regulators of human ophthalmic artery. Invest Ophthalmol Vis Sci

20 Ohkubo H, Chiba S. Vascular reactivities of isolated and perfused human ciliary arteries. Fpn f Pharmacol 1988;32:450-6.

21 Nyborg NCB, Nielsen PJ. The level of spontaneous myogenic tone in isolated human posterior ciliary arteries decreases with age. Exp Eye Res 1990;51:711-5.

22 Nyborg NCB, Nielsen PJ. Angiotensin-II contracts isolated human posterior ciliary arteries. Invest Ophthalmol Vis Sci 1990;31:2471-3.

23 Yu D-Y, Alder VA, Su E-N, Mele EM, Cringle SJ, Morgan WH. Agonist response of human isolated posterior ciliary artery. Invest Ophthalmol Vis Sci 1992;33:48-54.

24 Nyborg NCB, Nielsen PJ. Neurogenic nitric oxide accounts for the non-adrenergic non-cholinergic vasodilation in human posterior ciliary
arteries. ARVO Abstracts Invest Ophthalmol Vis Sci 1994;35:S1287.

25 Yao K, Tschudi M, Flammer J, Lüscher TF. Endothelium-dependent regulation of vascular tone of the porcine ophthalmic artery. Invest Ophthalmol 1991;32:1791-8

26 Haefliger IO, Flammer J, Lüscher TF. Heterogeneity of endotheliumdependent regulation in ophthalmic and ciliary arteries. Invest Ophthalmol Vis Sci 1993;34:1722-30.

27 Meyer P, Flammer J, Lüscher TF. Local anaesthetic drugs reduce endothelium-dependent relaxations of porcine ciliary arteries. Invest Ophthalmol Vis Sci 1993;34:2730-6.

28 Hester RK, Chen Z, Becker EJ, McLaughlin M, DeSantis L. The direct vascular relaxing action of betaxolol, carteolol and timolol in porcine long posterior ciliary artery. Surv Ophthalmol 1994;38:S125-34.

29 Meyer P, Lang M, Flammer J, Lüscher TF. Effects of calcium channel blockers on the response to endothelin-1 and sodium nitroprusside in porcine ciliary arteries. Exp Eye Res 1995;60:505-10.

30 Yu D-Y, Alder VA, Cringle SJ, Su E-N, Yu PK. Vasoactivity of intraluminal and extraluminal agonists in perfused retinal arteries. Invest Ophthalmol Vis Sci 1994;35:4087-99.

31 Nyborg NCB, Nielsen PJ, Prieto D, Benedito S. Angiotensin II does not contract bovine retinal resistance arteries in vitro. Exp Eye Res 1990;50:469-74.

32 Wiencke AK, Nilsson H, Nielsen PJ, Nyborg NCB. Nonadrenergic noncholinergic vasodilation in bovine ciliary artery involves CGRP and neurogenic nitric oxide. Invest Ophthalmol Vis Sci 1994;35:3268-77.

33 Nyborg NCB, Nielsen PJ. Beta-adrenergic receptors regulating vascular smooth muscle tone are only localised to the intraocular segment of the long posterior ciliary artery in bovine eye. Surv Ophthalmol 1995;39:S66-75. 34 Hoste AM, Boels PJ, Brutsaert DL, De Laey JJ. Effect of alpha-1 and beta
agonists on contraction of bovine retinal resistance arteries in vitro. Invest Ophthalmol Vis Sci 1989;30:44-50.

35 Nielsen PJ, Nyborg NCB. Calcium antagonist-induced relaxation of the prostaglandin-F2 response of isolated calf retinal resistance arteries. Exp Eye Res 1989;48:329-35.

36 Hoste AM, Boels PJ, Andries LJ, Brutsaert DL, De Laey JJ. Effects of betaantagonists on contraction of bovine retinal resistance arteries in vitro. antagonists on contraction of bovine retial
Invest Ophthalmol Vis Sci 1990;31:1231-7.

37 Nielsen PJ, Nyborg NCB. Contractile and relaxing effects of arachidonic acid derivatives on isolated bovine retinal resistance arteries. Exp Eye Res 1990;50:305-11.

38 Benedito S, Prieto D, Nielsen PJ, Nyborg NCB. Role of the endothelium in acetylcholine-induced relaxation and spontaneous tone of bovine isolated retinal small arteries. Exp Eye Res 1991;52:575-9.

39 Benedito S, Prieto D, Nielsen PJ, Nyborg NCB. Histamine induces endothelium-dependent relaxation of bovine retinal arteries. Invest Ophthalmol Vis Sci 1991;32:32-8.

40 Nyborg NCB, Prieto D, Benedito S, Nielsen PJ. Endothelin-1-induced contraction of bovine retinal small arteries is reversible and abolished by nitrendipine. Invest Ophthalmol Vis Sci 1991;32:27-31.

41 Ohkubo H, Chiba S. Pharmacological analysis of vasoconstriction of isolated canine ophthalmic and ciliary arteries to alpha-adrenoceptor agonists. Exp Eye Res 1987;45:263-70.

42 Ohkubo H, Chiba S. Responses of isolated canine ophthalmic and ciliary

43 Ohkubo H, Chiba S. Regional differences of vascular sensitivities in canine long posterior ciliary arteries. Curr Eye Res 1988;7:457-63.

44 Kitamura Y, Okamura T, Kani K, Toda, N. Nitric oxide-mediated retinal arteriolar and arterial dilatation induced by substance P. Invest Ophthalmol Vis Sci 1993;34:2859-65.

45 Yu D-Y, Alder VA, Su E-N, Cringle SJ. Relaxation effects of diltiazem, verapamil and tolazoline on isolated cat ophthalmociliary artery. Exp Eye Res 1992;55:757-66.

46 Yu D-Y, Su E-N, Alder VA, Cringle SJ, Mele EM. Pharmacological and mechanical heterogeneity of cat isolated ophthalmociliary artery. Exp Eye Res 1992;54:347-59.

47 Rockwood EJ, Fantes F, Davies EB, Anderson DR. The response of retinal vasculature to angiotensin. Invest Ophthalmol Vis Sci 1987;28:676-82.

48 Zschauer A, Van Breemen C, Uusitalo H. Serotonergic responses in rabbit ophthalmic artery: a pharmacological characterisation. Am f Physiol 1991; 261:H1819-27.

49 Zschauer A, Uusitalo H, Brayden JE. Role of endothelium and hyperpolarisation in CGRP-induced vasodilation of rabbit ophthalmic artery. $A m \mathcal{F}$ Physiol 1992;263:H359-65.

50 Vanhoutte PM, Miller VM. Heterogeneity of endothelium-dependent responses in mammalian blood vessels. F Cardiovasc Pharmacol 1985;7: Suppl 3, S12-23.

51 Furchgott RF. Role of endothelium in the responses of vascular smooth muscle. Circ Res 1983;53:557-72.

52 Furchgott RF, Zawadzki JV. The obligatory role of endothelial cells in the relaxation of arterial smooth muscle by acetylcholine. Nature 1980;299: 373-547.

53 Palmer RMJ, Ashton DS, Moncada S. Vascular endothelial cells synthesise nitric oxide from L-arginine. Nature 1988;333:664-6.

54 Rees DD, Palmer RMJ, Schulz R, Hodson HF, Moncada S. Characterisation of three inhibitors of endothelial nitric oxide synthase in vitro and in vivo. Br f Pharmacol 1990;101:746-52.

55 Rapoport RM, Murad F. Agonist induced endothelium-dependent relaxation in rat thoracic aorta may be mediated through cGMP. Circ Res 1983;
52:352-7.
56 Mann RM, Riva CE, Stone RA, Barnes GE, Cranstoun SD. Nitric oxide and choroidal blood flow regulation. Invest Ophthalmol Vis Sci 1995;36:925-30. 57 Deussen A, Sonntag M, Vogel R. L-arginine-derived nitric oxide: A major determinant of uveal blood flow. Exp Eye Res 1993;57:129-34.

58 Donati G, Pournaras CJ, Munoz J-L, Poitry S, Poitry-Yamade CL, Tsacopoulos M. Nitric oxide controls arteriolar tone in the retina of the miniature pig. Invest Ophthalmol Vis Sci 1995;36:2228-37.

59 Seligsohn EE, Bill A. Effects of $\mathrm{N}^{\mathrm{G}}$-nitro-L-arginine methyl ester on the cardiovascular system of the anaesthetised rabbit and on the cardiovascular response $1219-25$.

60 Toda N, Okamura T. Modification by $\mathrm{L}-\mathrm{N}^{\mathrm{G}}$-monomethylarginine (LNMMA) of the response to nerve stimulation in isolated dog mesenteric NMMA) of the response to nerve stimulation in isolate
and cerebral arteries. $\not p n ~ f$ Pharmacol 1990;52:170-3.

61 Toda N, Okamura T. Role of nitric oxide in neurally induced cerebroarterial relaxation. I Pharmacol Exp Ther 1991;258:1027-32.

62 Stone RA, Kuwayama Y, Laties AM. Regulatory peptides in the eye. Experientia 1987;43:791-800.

63 Yamamoto R, Bredt DS, Snyder SH, Stone RA. The localisation of nitric oxide synthase in the rat eye and related cranial ganglia. Neuroscience 1993; 54:189-200.

64 Flügel C, Tamm ER, Mayer B, Lütjen-Drecoll E. Species differences in choroidal vasodilative innervation: evidence for specific intrinsic nitrergic and VIP-positive neurons in the human eye. Invest Ophthalmol Vis Sci 1994;35:592-9.

65 Ohkubo H, Chiba S. Vascular reactivities of simian ophthalmic and ciliary arteries. Curr Eye Res 1987;6:1197-203.

66 Elena PP, Kosina-Boix M, Moulin G, Lapalus P. Autoradiographic localisation of beta-adrenergic receptors in rabbit eye. Invest Ophthalmol Vis Sci 1987;28:1436-41

67 Ferrari-Dileo G. Beta ${ }_{1}$ and beta $_{2}$ adrenergic binding sites in bovine retina and retinal blood vessels. Invest Ophthalmol Vis Sci 1988;29:695-9.

68 Kahle G, Kaulen P, Wollensak J. Quantitative autoradiography of $\beta$-adrenergic receptors in rabbit eyes. Exp Eye Res 1990;51:503-7.

69 Dzau VJ. Significance of the vascular renin-angiotensin pathway. Hypertension 1986;8:553-9.

70 Lüscher TF. Angiotensin, ACE-inhibitors and endothelial control of vasomotor tone. Basic Res Cardiol 1993;88:Suppl 1, 15-24.

71 Ferrari-Dileo G, Davis EB, Anderson DR. Angiotensin binding sites in bovine and human retinal blood vessels. Invest Ophthalmol Vis Sci 1987;28: $1747-51$.

72 Ferrari-Dileo G, Davis EB, Anderson DR. Angiotensin II binding receptors in retinal and optic nerve head blood vessels. An autoradiographic approach. Invest Ophthalmol Vis Sci 1991;32:21-6.

73 Ward PE, Stewart TA, Hammon KJ, Reynolds RC, Igic R. Angiotensin I converting enzyme (kininase II) in isolated retinal microvessels. Life Sci 1979;24:1419-24.

74 Igic R, Kojovic V. Angiotensin I converting enzyme (kininase II) in ocular tissues. Exp Eye Res 1980;30:299-303.

75 Ferrari-Dileo G, Ryan JW, Rockwood EJ, Davis EB, Anderson DR. Angiotensin-converting enzyme in bovine, feline and human tissues. Invest Ophthalmol Vis Sci 1988;29:876-81.

76 Wagner J, Danser AHJ, Derkx FHM, De Jong PTVM, Paul M, Mullins JJ, et al. Demonstration of renin mRNA, angiotensinogen mRNA, and angiotensin converting enzyme mRNA expression in the human eye: evidence for an intraocular renin-angiotensin system. Br f Ophthalmol 1996;80:159-63.

77 Danser AHJ, Van Den Dorpel MA, Deinum J, Derkx FHM, Franken AAM, Peperkamp E, et al. Renin, prorenin and immunoreactive renin in vitreous fluid from eyes with and without diabetic retinopathy. $\mathcal{F}$ Clin Endocrinol Metab 1989;68:160-6.

78 Constad WH, Fiore P, Samson C, Cinotto AA. Use of an angiotensin converting enzyme inhibitor in ocular hypertension and open-angle glaucoma. Am f Ophthalmol 1988;105:674-7.

79 Yanagisawa M, Kurihara H, Kimura S, Tomobe Y, Kobayashi M, Mitsui Y, et al. A novel potent vasoconstrictor peptide produced by vascular endothelial cells. Nature 1988;332:411-5.

80 Lerman A, Sandok EK, Hildebrand FF Jr, Burnett JC. Inhibition of endothelium-derived relaxing factor enhances endothelin-mediated vasocondothelium-derived relaxing factor enh

81 MacCumber MW, Jampel HD, Snyder SH. Ocular effects of the endothelins: abundant peptides in the eye. Arch Ophthalmol 1991;109:705-7.

82 Chakravarthy U, Douglas AJ, Bailie JR, McKibben B, Archer DB. Immunoreactive endothelin distribution in ocular tissues. Invest Ophthalmol Vis Sci 1994;35:2448-54.

83 Bill A, Sperber GO. Control of retinal and choroidal blood flow. Eye 1990;4: 319-25.

84 Flammer J. To what extent are vascular factors involved in the pathogenesis of glaucoma? In: Kaiser HJ, Flammer J, Hendrickson P, eds. Ocular blood flow: new insights into the pathogenesis of ocular diseases. Basel: Karger, 1996:
12-39.

85 Drance SM, Sweeney VP, Morgan RW, Feldman F. Studies of factors involved in the production of low-tension glaucoma. Arch Ophthalmol

86 Goldberg I, Hollows FC, Kass MA, Becker B. Systemic factors in patients with low-tension glaucoma. Br f Ophthalmol 1981;65:56-62.

87 Phelps CD, Corbett JJ. Migraine and low-tension glaucoma. A case control study. Invest Ophthalmol Vis Sci 1985;26:1105-8.

88 Drance SM, Douglas GR, Wijsman K, Schulzer M, Britton RJ. Response of blood flow to warm and cold in normal and low-tension glaucoma patients. Am $\mathcal{F}$ Ophthalmol 1987;105:35-9.

89 Gasser P, Flammer J. Blood cell velocity in the nailfold capillaries of patients with normal-tension and high-tension glaucoma. Am $\mathcal{f}$ Ophthalmol 1991;111:585-8.

90 Hoyng PFJ, De Jay N, Oosting H, Stilma J. Platelet aggregation, disc haemorrhage and progressive loss of visual fields in glaucoma. Int Ophthalmol 1992;16:65-73.

91 Klaver JHJ, Greve EL, Goslinga H, Geijssen HC, Heuvelmans JHA. Blood plasma viscosity measurements in patients with glaucoma. Br f Ophthalmol 1985;69:765-70.

92 Kaiser H, Flammer J, Went M, Lüscher TF. Endothelin-1 plasma levels in normal tension glaucoma: abnormal response to postural changes. Graefes Arch Clin Exp Ophthalmol 1995;233:484-8. 
93 Sugiyama T, Moriya S, Oku H, Azuma I. Association of endothelin-1 with normal tension glaucoma: clinical and fundamental studies. Surv Ophthalnormal tension glaucoma: clinical

94 Lerman A, Edwards BS, Hallett JW, Heublein DM, Sandberg SM, Burnett JC. Circulating and tissue endothelin immunoreactivity in advanced atherosclerosis. N Engl f Med 1991;325:997-1001.

95 Stewart DJ, Levy RD, Cernacek P, Langleben D. Increased plasma endothelin-1 in pulmonary hypertension: marker or mediator of disease? Ann Intern Med 1991;114:464-9.

96 McMurray JJ, Ray SG, Abdullah I, Dargie HJ, Morton JJ. Plasma endothelin in chronic heart failure. Circulation 1992;85:1374-9.

97 Stewart DJ, Cernacek P, Costello KB, Rouleau JL. Elevated endothelin-1 in heart failure and loss of normal response to postural change. Circulation 1992;85:510-7.

98 Zamora MR, O'Brien RF, Rutherford RB, Weil JV. Serum endothelin-1 concentrations and cold provocation in primary Raynaud's phenomenon. Lancet 1990;336:1144-7.

99 Toyo-oka T, Aizawa T, Suzuki N, Hirata Y, Miyauchi T, Shin WS, et al. Increased plasma level of endothelin-1 and coronary spasm induction in patients with vasospastic angina pectoris. Circulation 1991;83:476-83.

100 Qui S, Théroux P, Marcil M, Solymoss BC. Plasma endothelin-1 levels in stable and unstable angina. Cardiol 1993;82:12-9.

101 Geijer C, Bill A. Effects of raised intraocular pressure on retinal, preretinal, laminar and retrolaminar optic nerve blood flow in monkeys. Invest Ophthalmol Vis Sci 1979;18:1030-42.

102 Kiel JW, Shepherd P. Autoregulation of choroidal blood flow in the rabbit. Invest Ophthalmol Vis Sci 1992;33:2399-410.
103 Alm A. Ocular blood flow. In: Drance SM, ed. International symposium on glaucoma, ocular blood flow and drug treatment. Baltimore: Williams \& glaucoma, ocular blood
Wilkins, 1992:1-6.

104 Grunwald JE, Riva CE, Stone RA, Keates EU, Petrig BL. Retinal autoregulation in open-angle glaucoma. Ophthalmology 1984;91:1690-4

105 Anderson DR. Autoregulation in glaucoma. In: Drance SM, ed. International symposium on glaucoma, ocular blood flow and drug treatment. Baltimore: Williams \& Wilkins, 1992:82-9.

106 Harris A, Sergott RC, Spaeth GL, Katz JL, Shoemaker JA, Martin BJ. Colour Doppler analysis of ocular vessel blood velocity in normal tension glaucoma. Am f Ophthalmol 1994;118:642-9.

107 Butt Z, McKillop G, O'Brien CJ, Allan, P, Aspinall P. Measurement of ocular blood flow velocity using colour Doppler imaging in low-tension glaucoma. Eye 1995;9:29-33.

108 Rankin SJA, Walman BE, Buckley AR, Drance SM. Colour Doppler imaging and spectral analysis of the optic nerve vasculature in glaucoma. Am $\mathcal{F}$ Ophthlamol 1995;119:685-93.

109 Butt Z, O’Brien CJ, McKillop G, Aspinall P, Allan P. Colour Doppler imaging in untreated high and normal pressure open angle glaucoma. Invest imaging in untreated high and normal
Ophthalmol Vis Sci 1997;38:690-6.

110 Flammer J. The vascular concept of glaucoma. Surv Ophthalmol 1994;38: 3-6.

111 Nielsen PJ, Nyborg NCB. Effects of prostaglandins in bovine isolated aqueous veins. ARVO Abstracts Invest Ophthalmol Vis Sci 1996;37:S843.

112 Van Buskirk EM. Glaucoma, ocular blood flow and drug treatment. In: Drance SM, ed. International symposium on glaucoma, ocular blood flow and drug treatment. Baltimore: Williams \& Wilkins, 1992:7-16. 